\title{
Procesos de laicización en Santa Fe (Argentina): 1860-1900. Consideraciones sobre la «Argentina liberal y laica» ${ }^{1}$
}

\author{
por \\ Diego A. Mauro² \\ CONICET/Universidad Nacional de Rosario, Argentina
}

\begin{abstract}
El presente articulo plantea la necesidad de avanzar en la construcción de una historia de la secularización y la laicidad en la Argentina. En dicho marco se resalta la importancia de indagar más rigurosamente los procesos de laicización que, con diferentes modalidades, se desarrollaron a lo largo de la segunda mitad del siglo XIX. Partiendo de este diagnóstico, el artículo aborda puntualmente el caso de la provincia de Santa Fe entre las décadas de 1860 y 1900, período en el que -siguiendo la conceptualización de Jean Baubérot- toma forma lo que cabría definirse como un «segundo umbral de laicidad».

Palabras ClaVe: secularización; laicización; umbral de laicidad; matrimonio civil; Iglesia Católica.
\end{abstract}

En los últimos años, el debate en torno a los retos y desafíos de la laicidad ha llamado la atención sobre la necesidad de encarar con mayor detenimiento y rigor conceptual una historia de la secularización y la laicidad en la Argentina. Puestas en tensión las teorías más ideológicas de la secularización, las últimas décadas han abierto nuevos interrogantes acerca de los procesos múltiples de tránsito de los regímenes de cristiandad a las formas de moder-

${ }^{1}$ Una versión anterior del presente trabajo se presentó como ponencia en el marco de las XI Jornadas de Historia: Clericales y anticlericales, un siglo de controversias, realizadas en la Universidad Torcuato Di Tella (Buenos Aires), durante septiembre de 2011. Agradezco los comentarios recibidos en aquella ocasión.

2 Investigador del Consejo Nacional de Investigaciones Científicas y Técnicas (CONICET) y docente en la Universidad Nacional de Rosario, Argentina. E-mail: diegomauro@ conicet.gov.ar 
nidad religiosa ${ }^{3}$. Entre ellos, los referidos a los llamados procesos de laicización, a través de los cuales la autoridad estatal absorbió funciones e instituciones previamente bajo la órbita católica.

En el caso argentino, dichos procesos se asocian a las llamadas «leyes laicas» de la década de 1880 y -como en otros países de Hispanoamérica- al «clásico» enfrentamiento entre «católicos y liberales» ${ }^{4}$. Con el correr de los años, tomó fuerza un modelo explicativo y una periodización que a esta altura se han vuelto un lugar común: a la Argentina liberal -vigente entre 1880 y 1930 - le habría seguido una Argentina católica, resultado de la crisis del orden liberal en torno a la cisura de 1930 y del advenimiento de un catolicismo de «conquista». Según dicho modelo, que comparten también en buena medida los historiadores católicos o confesionales, la «laicidad liberal»se habría impuesto a lo largo de dichas décadas hasta el advenimiento de la «Argentina católica». ${ }^{5} \mathrm{La}$ interpretación -que sintoniza con otras a escala hispanoamericana- alcanzó una gran influencia y goza actualmente de aceptación tanto por quienes estudian el período como por numerosas investigaciones que la confirman de manera especular, presentando la Argentina liberal como el punto de partida para explorar la «ruptura» del treinta y el llamado «renacimiento católico». En el último tiempo, sin embargo, a la luz de nuevas investigaciones y perspectivas teóricas el modelo comenzó a despertar algunas dudas.

En primer lugar, se ha puesto en tela de juicio uno de sus «punto de llegada»: la idea de «renacimiento católico». Lejos de permanecer aletargado durante el llamado período «liberal», investigaciones recientes sugieren que el catolicismo -tanto a nivel de sus estructuras parroquiales como de sus organizaciones de laicos- se expandió vigorosa y aceleradamente desde fines del siglo XIX. Lo mismo, por cierto, cabría señalarse de su capacidad de movilización y ocupación del espacio público. La ebullición de los treinta y la «Argentina católica» se explicarían entonces más por las continuidades que por las rupturas 6 .

En segundo lugar, se ha comenzado a revisar también la idea de que entre 1880 y 1930 la «laicidad liberal» -aun entendiéndola como un tipo ideal o, en términos de Blancarte, como un proceso continuo- habría sido hegemóni-

3 Una buena puesta al día de los debates teóricos contemporáneos en: Woodhead, 2001. Diotallevi, 2001.

${ }^{4}$ Lynch, 1991.

5 Entre otros: Mallimaci, 2007; 2004; 2001.

${ }^{6}$ En esta línea: Lida y Mauro, 2009. Lida, 2010. Mauro, 2010. 
ca a nivel del Estado y sus élites políticas7. Diferentes historiadores, entre ellos Lilia Ana Bertoni, Loris Zanatta, Roberto Di Stefano y Fernando Devoto, han demostrado que los vientos laicistas menguaron bastante pronto -ya en la década de 1890 - y que incluso en la década laica por excelencia, los iniciativas laicizadoras se concentraron, en realidad, en momentos puntuales y en torno a problemas concretos derivados de las transformaciones sociales y económicas auspiciadas por la inmigración y la inserción de la Argentina en el mercado mundial: los debates en torno a la ley 1420 entre 1882 y 1884 y la ley de matrimonio civil en 1888. Las provincias, por su parte, incluso en dichos momentos se mostraron reticentes a debatir sobre la educación laica, manteniendo la enseñanza religiosa en sus leyes y planes de estudio. A principios del siglo XX, también en la ciudad de Buenos Aires y en el parlamento nacional el ímpetu laicista mermó considerablemente. El proyecto de ley de divorcio de 1902 -fuertemente resistido por los católicos- no logró ya ser sancionado y las lecturas catolizantes del pasado nacional comenzaron a ganar mayor predicamento en las élites políticas.

Finalmente, como ha señalado recientemente Roberto Di Stefano, caracterizar al laicismo argentino de aquellas décadas como «liberal» plantea ciertamente dificultades no menores ${ }^{8}$. No sólo porque en los hechos las fronteras entre «católicos» $\mathrm{y}$ «liberales» fueron siempre altamente permeables y porosas incluso en los momentos de más alta conflictividad sino fundamentalmente porque la extendida homologación entre «liberalismo»y «laicismo» confunde posiciones muy diferentes en cuanto al modo de pensar las relaciones entre la religión católica y el Estado. En principio, al menos dos: la de aquéllos que defienden la separación de la Iglesia y del Estado y postulan la neutralidad religiosa; y la de quienes, por el contrario, consideran necesario conservar incólumes los mecanismos del patronato que garantizan el control del Estado sobre la Iglesia9. En Argentina, los llamados «liberales» reservaron para el culto católico un carácter cuasi oficial y a la Iglesia Católica, a diferencia de las demás, el rango de institución de derecho público ${ }^{10}$. Lo cual, argumenta Di Stefano, mostraría la falta de consenso en torno a las posturas más clásicamente liberales incluso en el cénit de la «Argentina liberal», dando cuenta, por el contrario, de la pregnancia de corrientes galicanas de larga

7 Blancarte, 2008: 144.

8 Sobre el concepto de «liberalismo clásico» para el caso argentino: Gallo, 2008.

9 Sobre la cuestión del patronato: Martínez, 2010.

${ }^{10}$ Como bien muestra Blancarte, en Hispanoamérica el postulado de la neutralidad religiosa del Estado y el establecimiento de las Iglesias como instituciones de derecho privado sólo fue perseguido en casos y momentos puntuales. Blancarte, 2008. 
data $^{11}$. En consecuencia, a diferencia de lo ocurrido en Francia, Brasil, México, Chile o Uruguay, la Argentina no separaría finalmente -al menos en términos constitucionales- Iglesia y Estado.

En el marco de este debate, se hace entonces preciso estudiar más detenidamente las iniciativas laicizadoras y los procesos de construcción de laicidades que, con diferentes características y modalidades, se desarrollaron en las provincias argentinas a lo largo de la segunda mitad del siglo XIX y, particularmente, en torno a la denominada «Argentina liberal». Partiendo de estos presupuestos, en las páginas que siguen nos ocuparemos de la provincia de Santa Fe entre las décadas de 1860 -cuando se sanciona la primera ley de matrimonio civil y municipalización de cementerios- y la de 1890 , cuando tras la sanción de las «leyes laicas» se establece finalmente a nivel nacional lo que -siguiendo a Jean Baubérot- cabría definirse como un segundo umbral de laicidad ${ }^{12}$.

El gobierno de Nicasio Oroño. Entre la materialización Del «PRimer UMBRAL» Y LA CONSTRUCCIÓN DEL «SEGUNDO»

El gobierno de Oroño se convirtió en motivo de grandes controversias y animó encendidos debates hasta bien entrado el siglo XX. En consonancia con las proclamas del Obispo Gelabert de la Diócesis del Litoral, los católicos acusaron a Oroño de «anticlerical» y «anticatólico» y de desatar la persecución religiosa. Desde entonces, su figura se convirtió en uno de los ejemplos más frecuentemente esgrimidos por obispos e intelectuales católicos para ilustrar las supuestas amenazas que se cernían ante el avance de la apostasía y la incredulidad en las élites dirigentes. Por el contrario, para quienes desde las logias masónicas y hacia fines del siglo XIX desde los centros de librepensamiento impulsaban la separación de la Iglesia y el Estado, su figura adquirió rasgos apoteósicos. Sobre todo entre los librepensadores, Oroño fue convertido -tal como lo acusaba Gelabert- en un ferviente «anticlerical» y «antirreligioso» dispuesto a luchar a capa y espada por la separación de la Iglesia y del Estado y por la retracción de la religión al mundo privado, paso previo, afirmaban las voces más entusiastas, para su definitiva oclusión a manos del pensamiento científico.

11 Las críticas pueden seguirse en: Di Stefano, 2011a; 2011b. Sobre las corrientes galicanas: Di Stefano, 2004; 2008.

12 Una apretada síntesis del modelo teórico en: Baubérot, 2010. En relación con el caso argentino: Di Stefano, 2011a. 
Las medidas tomadas, sin embargo, como el propio Oroño recalcaba, respondían a razones mucho menos ideológicas o combativas. Lejos de toda actitud anticatólica o antirreligiosa y a una prudente distancia también de lo que cabría definirse como un modelo de «secularización liberal», el gobierno de Oroño -como el de su antecesor Patricio Cullen- estrechó relaciones con el clero y el obispo de Paraná, a cuya consagración, por ejemplo, contribuyó económicamente en 1865. En un momento en que las estructuras eclesiásticas de la provincia eran extremadamente precarias, el gobierno de Oroño destinó recursos vitales para el levantamiento de templos y el financiamiento de parte del clero $^{13}$. En un ejemplo de ello, en 1864, actuando como gobernador delegado otorgó al cura de San José -a instancias de un pedido de Gelabertuna subvención mensual y una suma extraordinaria para realizar obras de mantenimiento en la capilla. En igual sentido, entre 1865 y 1868 se construyeron o refaccionaron con recursos estatales los templos de Helvecia, Sauce, San Gerónimo, San José de la Esquina y Rosario, y se realizaron reparaciones en la Iglesia Matriz ${ }^{14}$. El propio Oroño se hizo presente incluso en la colocación de la piedra fundamental de la Iglesia del Carmen -que había recibido donaciones del Estado provincial-, resaltando la importante labor civilizatoria del clero y la centralidad de la religión para el orden social ${ }^{15}$. En la ocasión, se permitió pedir también por un clero más «ilustrado» que -como habían imaginado casi un siglo antes los Borbones- contribuyera al progreso económico, transmitiendo en la campaña -y sobre todo a los colonos recién llegados- conocimientos útiles para la puesta en producción de la tierra. Otorgó también, como su antecesor, becas y bonos de edificación pública para sostener los colegios católicos existentes: el de la Inmaculada Concepción en Santa Fe y el de las Hermanas de la Caridad en Santa Fe y Rosario.

Al menos a lo largo de sus tres primeros años de gobierno -en 1864 como gobernador delegado- no hubo indicios de conflictos de ninguna naturaleza ni se tomaron medidas que generaran roces. Por el contrario, Oroño contribuyó considerablemente a sostener el proceso de creación de capellanías que impulsaba Gelabert, haciendo del precario Estado provincial un vector que alimentaba la construcción especular de la Iglesia.

13 Sobre el gobierno de Oroño: Simian, 2004. Sonzogni, 2004. Un recorrido más general por su vida política, incluido su mandato como gobernador: De Marco, 2004. Desde una perspectiva confesional dirigida a alimentar el llamado «mito de la nación católica» pero con valiosos aparatos eruditos: Bruno, 1981, vol. VII. Furlong, 1962, vols. III y IV.

${ }^{14}$ Mensaje del Sr. Gobernador Nicasio Oroño a la Legislatura, documento de archivo editado en AA.VV., 1973b, vol. VI.

15 Carta del Pbro. José María Zattoni al Obispo de Paraná, 31/10/1864, Archivo del Arzobispado de Santa Fe, Santa Fe, Argentina (AASF), caja Parroquia Del Carmen. 
El primer incidente ocurrió recién en agosto de 1866 cuando el Rector del Colegio de la Inmaculada, el jesuita Pedro Vigna, se negó a permitir la inspección de la Comisión Municipal de Enseñanza a través de la cual el gobierno se proponía comenzar a regular y ordenar la educación provincial. El gobierno amenazó con cesar la subvención acordada y Vigna dio entonces por terminado el contrato firmado algunos años antes con Patricio Cullen. A pesar de los roces y amenazas, la sangre no llegó al río y pronto se llegó a un nuevo acuerdo: de allí en más cesarían en parte las subvenciones y becas pero se mantendrían las ya entregadas y, lo más importante, se terminarían las obras en curso en el edificio. Las tensiones disminuyeron y Oroño minimizó el choque destacando en su mensaje a la legislatura la importancia de los jesuitas en la educación y el progreso de la provincia. ${ }^{16}$

Los conflictos se desataron en realidad poco después, tras el conocido intento por transformar el Convento de San Carlos en una Escuela Agrícola -finalmente rechazado por la legislatura- y, fundamentalmente, con la municipalización de los cementerios y la ley de matrimonio civil ${ }^{17}$. El obispo Gelabert desde Paraná y Félix Frías desde Buenos Aires atribuyeron a Oroño un liberalismo anticatólico y sectario y pidieron detener el «torrente de impiedad» y los «ataques contra el sacerdocio y la religión». Ninguna de las medidas tomadas, sin embargo, apelaba a argumentos antirreligiosos o anticatólicos como tampoco a concepciones netamente «liberales», al menos en lo referido a las relaciones Iglesia-Estado. Oroño, de hecho, intentó desde un primer momento «desideologizar» las medidas presentándolas como «hijas de la necesidad», cuyo único propósito era asegurar el éxito del proceso de colonización que, insistía, todos apoyaban y en el cual la Iglesia ocupaba un lugar de suma relevancia que nadie pretendía menoscabar.

En términos de secularización y viendo las cosas en perspectiva, las tensiones ponían en evidencia, más allá de los pormenores del conflicto, el mayor grado de materialidad adquirido por el llamado «primer umbral». Hasta entonces, o al menos hasta mediados de la década de 1850, los gobernantes de Santa Fe no habían tenido que enfrentar en los hechos el resquebrajamiento de la unidad entre ciudadanos y fieles, roto sólo en términos tendenciales tras la revolución. Al margen de la voluntad y las ideas de Oroño o del Club Libertad, el conflicto expresaba los desafíos planteados por la encarnación de esa ruptura abstracta en colonos de carne y hueso, franceses, suizos, alemanes, belgas e italianos que en muchos casos no profesaban

16 Mensaje del Sr. Gobernador Nicasio Oroño a la Legislatura, 25 de mayo de 1867, documento de archivo editado en AA.VV., 1973b, vol. VI: 212-213.

17 Sobre el conflicto en torno al Convento: De Marco, 2004: 23-25. 
la fe católica. En otras palabras, tras más de medio siglo, por primera vez, ese primer umbral de laicización en construcción desde la revolución comenzó a dar pie -colonización mediante- a cambios profundos en la fisonomía religiosa de Santa $\mathrm{Fe}^{18}$.

De hecho, las primeras dificultades se hicieron evidentes ya con la fundación misma de las colonias de Esperanza en 1856 y San Carlos en 1858 cuando se debió encontrar fórmulas que permitieran transitar sin conflictos la libertad de cultos. El gobierno optó entonces por enfrentar el problema pragmáticamente aportando fondos públicos tanto para templos católicos como protestantes. La estrategia fue relativamente exitosa y limó asperezas por un tiempo pero pronto, con el surgimiento de nuevas colonias y el crecimiento de las existentes, los desafíos se multiplicaron irremediablemente. El enterramiento de los no católicos y el surgimiento de matrimonios mixtos generaron nuevos frentes de tormenta y acabaron motivando altercados públicos. En 1864, el juez de paz de Esperanza, por ejemplo, denunció al pastor protestante por celebrar casamientos mixtos violentando las leyes católicas, a lo que un grupo de colonos protestantes respondió pidiendo la cabeza del juez de paz. Poco después, el cura párroco de la Iglesia Matriz de Santa Fe se negó a casar a un vecino por pertenecer a una logia masónica y lo mismo comenzó a ocurrir en los cementerios dónde los curas se negaban a dar sepultura a masones y protestantes ${ }^{19}$.

Oroño, consciente de los riegos que implicaba la municipalización de los cementerios, presentó la ley con sumo cuidado, recalcando que no lo animaba ninguna oposición a la Iglesia, a la que por el contrario le reconocía un rol central en la materia, sino la necesidad de llevar un registro fidedigno de las defunciones asegurando, además, enterramiento a los colonos protestantes.

Tras su sanción y reglamentación, comenzaron a producirse conflictos en diferentes puntos de la provincia. El cura de Villa Constitución se negó a entregar el cementerio al juez de paz y por orden del Ministerio de Gobierno fue encarcelado en Rosario. El de San Jerónimo renunció y el de San José de la Esquina se ausentó sin entregar la llave de la capilla ni del cementerio, acusando a Oroño de masón y hereje. Se entablaron entonces negociaciones 2005.

18 En relación con el proceso colonizador: Gallo, 2004. Bonaudo, 2006. Barsky y Gelman,

19 En las décadas previas las relaciones con la masonería no habían causado problemas. De hecho, las investigaciones disponibles muestran que las logias estaban integradas mayoritariamente por católicos. Desde fines de la década de 1850 las relaciones se hicieron, no obstante, más tensas consecuencia tanto del crecimiento e influencia de las logias como del desarrollo y difusión del llamado «catolicismo intransigente». Bonaudo, 2007. Di Stefano, 2010: 197-211. 
con el provisor y vicario general que, más allá del discurso intransigente de Gelabert, se mostró dispuesto a buscar un acuerdo. Según el provisor, la cuestión central no pasaba tanto por la municipalización de los cementerios como por el cobro que la Iglesia hacía de una tasa eclesiástica y que la municipalización pretendía estatizar. Según el enviado de Gelabert, interferir con dichas tarifas violentaba derechos irrenunciables de la Iglesia porque la paga no era por el enterramiento sino por los servicios religiosos. En su opinión, el problema podía zanjarse si el gobierno aceptaba ese «derecho» y le aseguraba al Obispado del Litoral que, al margen de la municipalización y del cobro del «boleto de entierro» por parte del Estado, el clero seguiría recibiendo la tarifa en cuestión.

Mientras el asunto se negociaba, la Legislatura sancionó el proyecto de matrimonio civil enviado por el Poder Ejecutivo poco antes -a fines de septiembre de 1867- y el conflicto subió de voltaje. Según las crónicas de Ramón Lassaga, la ley -fuertemente impugnada por Gelabert a través de una «protesta y declaración» públicas- desató movilizaciones en Santa Fe al grito de «mueran los masones». La misma noche de su sanción -según El Eco de Córdoba- se produjeron protestas ${ }^{20}$. Los incidentes se multiplicaron: algunos párrocos ordenaron a los fieles desconocer la ley y Gelabert excomulgó públicamente a los poderes ejecutivo y legislativo. Según su «Protesta» se trataba de una ley anticristiana, anticatólica e inconstitucional. El gobierno, por su parte, abandonó la posición negociadora, denunció el acto como «subversión» y desconoció la capacidad del obispo para «excomulgarlo». Según Oroño, Gelabert cometía un error canónico y desconocía las propias leyes de la Iglesia porque no podía «fulminarse excomunión mayor» sin atenerse a la realización del «proceso» previsto por las leyes eclesiásticas $^{21}$. El conflicto siguió in crescendo y la policía se presentó en el Colegio de la Inmaculada reclamando la entrega de las copias de la protesta del obispo. Lo mismo ocurrió poco después en los conventos de San Francisco y Santo Domingo. En Coronda, Calchines, San Carlos y San José de la Esquina se detuvo incluso a los curas y en algunos casos a los sacristanes acusados de difundir el documento ${ }^{22}$. Aunque todos fueron rápidamente liberados, el conflicto con el cura de Villa Constitución se prolongó. Oroño emitió entonces un decreto suspendiéndolo en su cargo y ordenándole a

20 Bruno, 1981, vol. VII: 322-323.

21 Decreto sobre la protesta del obispo de Paraná, $1^{\circ}$ de octubre de 1867 , documento de archivo editado en Apéndice núm. 7 de Videla y Wexler, 2004: 53 y 54.

22 Carta del Pbro. Julián Garcilazo al Secretario del Obispado de Paraná, 08/10/1867, AASF, Caja Parroquia de Coronda. 
Gelabert nombrar a un reemplazante ${ }^{23}$. En Esperanza y San Jerónimo se vivieron situaciones parecidas y los jesuitas José Auweiler y Federico Tewes, recién llegados a Santa Fe, fueron detenidos. Finalmente, el gobierno encarceló también a dos opositores vinculados al Club del Pueblo, Eudoro Carrasco y Servando Bayo, por imprimir en Rosario la conflictiva pastoral y llamar a la movilización ${ }^{24}$.

El clima de tensión, propiciado por las detenciones pero también por el rumor de que el Club del Pueblo estaba reuniendo «indios» y «gauchos» para una «revolución», disparó la alarma de Oroño, quien intentó calmar los ánimos explicando nuevamente que el matrimonio civil no afectaba las creencias católicas y que su único objetivo era asegurar el «establecimiento de las Colonias». Casi inmediatamente, los rumores dieron paso a los hechos y el gobierno debió enfrentar alzamientos armados en Santa Fe y Rosario, encabezados por líderes del Club del Pueblo, entre ellos Simón de Iriondo. Aunque en un primer momento el alzamiento fue repelido, Oroño se vio obligado a delegar el gobierno en dos ocasiones ante la persistencia del movimiento. Apoyado por el presidente Mitre volvió a tomar posesión del cargo en enero de 1868 pero, poco después, nuevos alzamientos lo obligaron a delegar por segunda vez el gobierno cuando sólo faltaban escasas semanas para la realización de las elecciones a gobernador. En dicho contexto, el Club del Pueblo -apoyado por Urquiza- logró imponerse en las elecciones de abril de 1868 a través de Mariano Cabal, alineando a Santa Fe con la candidatura del entrerriano y rechazando los acercamientos previos de Oroño y Alsina ${ }^{25}$.

23 Decreto de Oroño procesando al cura Vossen, 17 de septiembre de 1867, documento de archivo editado en Videla y Wexler, 2004: 83.

24 Sobre la situación de los jesuitas de las colonias: Furlong, 1962, vol. II: 258-263.

25 A fines de diciembre de 1867, las Guardias Nacionales al mando del coronel José Rodríguez lanzan un ataque sobre Santa Fe ante el cual Oroño pide la intervención nacional. Finalmente anula el pedido porque los revolucionarios aceptan un ofrecimiento de amnistía pero poco después estalla un segundo movimiento en Rosario dirigido por el coronel Patricio Rodríguez. El jefe político Ruiz Moreno escapa y la ciudad es tomada. Cuando llega la intervención de Buenos Aires los sediciosos se someten. El 4 de enero reasume Oroño y Simón de Iriondo, que actuaba como gobernador delegado, presenta la renuncia. El conflicto, sin embargo, continúa. El 9 de enero un grupo de sediciosos declara acéfalo el gobierno y entrega el mando al presidente de la Cámara de Justicia, José Grana, un urquicista reconocido, y junto a él asume Simón de Iriondo como ministro de gobierno. Mitre, que apoya a Oroño, desconoce las medidas y envía nuevamente tropas para tomar Rosario por la fuerza. El 27 de enero Oroño vuelve a ocupar su cargo pero como los rebeldes no han sido desarmados decide no salir de la ciudad ni convocar a elecciones por lo que la legislatura nombra gobernador interino a Camilo Aldao. Oroño vuelve a Santa Fe pero en los alrededores de la ciudad capital se desatan movilizaciones armadas bajo la supuesta dirección de Simón de Iriondo. El 23 
El cambio de timón dado por la provincia en el orden nacional, sugiere -como concluyen Ruiz Moreno y De Marco, entre otros- que si bien el alzamiento se vio sin dudas favorecido por el conflicto con Gelabert, su propósito principal no era derogar las conflictivas leyes sino apoyar la candidatura de Urquiza. Alzamientos similares se produjeron en Córdoba y Tucumán también motivados por la coyuntura electoral. Según Ruiz Moreno, además, la elección de Cabal como gobernador, quien había votado a favor de la ley de matrimonio civil y por ende no era bien visto por la curia de Paraná, confirmaría que, al menos en un primer momento, la prioridad de la revolución no era dar solución a la cuestión religiosa sino catapultar al Club del Pueblo al poder, alineando a la provincia tras la candidatura de Urquiza.

DE LA «REVOluCión» A LAS LEYES LAICAS DE LA DÉCADA DE 1880:

LA CONSTRUCCión de un SEgundo umbral de laicidad en SANTA Fe

Tras apoyar la finalmente derrotada candidatura de Urquiza, los revolucionarios, que debían en parte su triunfo al conflicto religioso, dieron muestras claras de aspirar a restablecer buenas relaciones con el clero. La legislatura derogó entonces la conflictiva ley de matrimonio civil y el flamante gobernador Cabal -que, como señalamos, la había apoyado sólo unos meses antes-dio otra clara señal a la curia de Paraná restituyendo al cura de Villa Constitución en «justa satisfacción» y dedicando poco después elogiosas palabras de reconocimiento a la labor de la Iglesia. Simón de Iriondo, una de las cabezas visibles del alzamiento, ocupó el Ministerio de Gobierno primero y sucedió a Cabal después, reproduciendo juicios igualmente favorables en innumerables ocasiones. La relación con Paraná se volvió cercana y fluida. Ambos, además, financiaron de manera continuada las ampliaciones del Colegio de la Inmaculada y destinaron partidas especiales al Colegio del Huerto en Rosario que, dicho sea de paso también Oroño había impulsado, y realizaron donaciones para la construcción o ampliación de templos ${ }^{26}$. Por decreto, además, a principios de 1872, el control de las obras de construcción, reforma o amplia-

entrega el mando a Aldao y es nombrado senador nacional. Poco después, todavía en un clima de enfrentamiento, es electo Mariano Cabal e Iriondo asume como ministro de gobierno. Ruiz Moreno, 2006.

${ }^{26}$ Mensaje del Sr. Gobernador Mariano Cabal a la Legislatura, 11 de junio de 1869; Mensaje del Sr. Gobernador Simón de Iriondo a la Legislatura, 21 de mayo de 1871 y 8 de junio de 1873, documentos de archivo editados en AA.VV., 1973b, vol. VI: 246-247, 286 y 323-324. Carta de Simón de Iriondo al Obispo de Paraná, 13/09/1871, AASF, caja Iglesia Matriz/Todos los Santos. 
ción de templos así como la designación de las comisiones encargadas pasaron a manos del obispo ${ }^{27}$. La creación de capellanías y la construcción de templos adquirieron un ritmo más intenso, con construcciones simultáneas en diversas localidades entre ellas Totoras, Barracas, Santo Tomé, Gaboto y Rosario $^{28}$. A partir de 1873, Iriondo impulsó también la creación del Colegio de Santa Rosa en Rosario que, habilitado para dar clases superiores equivalentes a las de los Colegios Nacionales, incluyó en sus planes oficiales las asignaturas de religión demostrada, teología e historia sagrada. Hacia el final de su mandato, Iriondo volvió a defender la importancia de la construcción de templos para el «progreso» de las colonias, razón por la cual, según explicaba a Gelabert, continuaría comprometiendo todo lo necesario para llevar a buen puerto la tarea.

A pesar de la derogación de la ley de matrimonio civil y la creciente imbricación entre Estado provincial e Iglesia auspiciada por el Club del Pueblo, el «retroceso» en términos de laicidad no fue total. La municipalización de los cementerios se mantuvo parcialmente en vigencia -aunque se sancionaron nuevas reglamentaciones- y la resolución que a poco de asumir Cabal derogó la ley de matrimonio civil pedía avanzar en el mediano plazo con una solución legal para los matrimonios protestantes y los consumados entre católicos y practicantes de otros cultos. Problema que se reconocía como merecedor de una solución pronta en el marco de una sociedad que ya no se ajustaba a un régimen de cristiandad.

En los años venideros, este piso de laicidad no se modificó aunque los vínculos con la Iglesia se hicieron más estrechos. Con Servando Bayo, a quien Oroño había encarcelado en 1867 por imprimir la pastoral de Gelabert, los subsidios al Colegio de la Inmaculada, dónde se proyectaba instalar con el aval de los jesuitas una Universidad Provincial, crecieron substancialmente. En 1877, el proyecto comenzó a tomar forma y Bayo presentó en la legislatura un primer diseño de la Universidad, compuesta por cuatro facultades entre las que se contaba una de Teología y Ciencias Sagradas ${ }^{29}$. En la ocasión refiriéndose específicamente a la religión argumentó que si bien el credo se reservaba a la conciencia individual, el gobierno debía seguir fundando las instituciones políticas en «el sentimiento religioso» contribuyendo a mantener de esa manera «todo lo posible la unidad de creencias, como elemento de

27 Carta de Simón de Iriondo al Obispo de Paraná, 02/01/1872, AASF, caja Parroquia de Coronda.

28 Bruno, 1981, vol. VII: 332-335.

29 Sobre el proyecto de Bayo, Furlong, 1962, vol. III y IV: 488-505. 
unidad política y social $»^{30}$. En la misma línea, durante su segundo mandato, Simón de Iriondo consideró que la religión era la base del orden social, moral y económico y propuso en consecuencia aumentar las partidas especiales -según acuerdos celebrados con Gelabert- para la construcción y reparación de templos ${ }^{31}$.

Finalmente, durante la década laica por excelencia, las cosas tampoco cambiaron substancialmente en Santa Fe. Haciendo gala de una retórica intransigente ya más definida, Gelabert rechazó las «leyes laicas» a nivel nacional pero, a diferencia de lo que había ocurrido en tiempos de Oroño, primó la calma y no se produjeron incidentes de envergadura.

Las diferencias entre ambos escenarios respondían al menos a dos razones. Por un lado, a que, más allá de las retóricas de combate que esgrimía el catolicismo intransigente, la Iglesia misma parecía reconocer, en un cierto grado, la inevitabilidad de algunos cambios, como por ejemplo la creación de un Registro Civil o la estatización de los cementerios. Incluso el matrimonio civil parecía no despertar ya tantas resistencias, con excepción de la cláusula que establecía su celebración como requisito para la consumación del matrimonio sacramentado, tal como - por cierto- también había ocurrido en tiempos de Oroño.

Por otro, al hecho fundamental de que la cuestión que más revuelo causaba, la ley de educación laica, no parecía tener defensores de peso en los poderes de la provincia. La llamada «opinión liberal», desde El Mensajero en Rosario, se mostró a favor y la pluma anticlerical de Deolindo Muñoz mereció varios llamados de atención de parte del clero pero, en general, las élites gobernantes de la provincia exhibieron más bien un amplio consenso a la hora de rechazar las aristas laicizadoras de la ley $1420^{32}$. De hecho, ya durante los debates del Congreso Pedagógico, el vicegobernador Cándido Pujato -en reemplazo del gobernador Zavalla- se ocupó de despejar dudas destacando una vez más el aporte jesuita al progreso y explicando que el Estado provincial seguiría ofreciendo «todo su apoyo» a la Iglesia y al Colegio de la Inmaculada y, de igual manera, durante la convención constituyente de 1883 la reli-

30 Mensaje del Sr. Gobernador Servando Bayo a la Legislatura, 3 de mayo de 1877, documento de archivo editado en AAVV., 1973b, vol. VI: 28-29.

31 Mensaje del Sr. Gobernador Simón de Iriondo a la Legislatura, 25 de mayo de 1878 y 15 de mayo de 1881, documento de archivo editado en AA.VV., 1973b, vol. VI: 82-83 y 109.

32 Sobre el discurso de la facción capitaneada desde Rosario por Deolindo Muñoz y sus vínculos con El Mensajero, Pasquali, 1997; 2003. 
gión católica fue reconocida como la base del orden social sin resistencias ${ }^{33}$. Poco después, el gobierno de Gálvez promulgó dos nuevas leyes de educación, una en 1884 y otra en 1886, que en consonancia con la ley 1420 incorporaban la obligatoriedad y la gratuidad -ya presentes dicho sea de paso en la ley que Oroño había sancionado en 1866- pero rechazaban la laicidad. La ley de 1884 declaraba como «primordial» la enseñanza religiosa y lo mismo hacía la de 1886 que la incorporaba, además, entre los contenidos mínimos que debían impartirse en el horario de clases. En Rosario, el Consejo Escolar Municipal propuso un reglamento propio que reemplazó la enseñanza de religión por una versión más laicizada denominada «moral y urbanidad», pero su disolución en 1890 devolvió las escuelas de su órbita al Consejo Provincial regido por la ley de 1886.

Desde el gobierno, además, se dieron por entonces otras claras señales a favor de la Iglesia, impulsando de manera más orgánica la construcción de templos y colegios católicos a través de exenciones impositivas para aquellos colonizadores o empresas colonizadoras que donaran terrenos con dichos fines. La ley dio sus frutos y entre 1887 y 1891 se escrituraran más de cuarenta terrenos en diferentes puntos de la provincia a favor de la futura diócesis de Santa $\mathrm{Fe}^{34}$.

El único conflicto de cierta envergadura se produjo con el Colegio de la Inmaculada. Hasta entonces, el Ministerio de Instrucción Pública de la Nación había equiparado sus títulos a los de los Colegios Nacionales, medida revocada durante la gestión de Eduardo Wilde. El Ministerio argumentaba que los programas de los jesuitas no se ajustaban a los cánones de los Colegios Nacionales y se consideraba, además, que el gobierno provincial no ejercía el debido control sobre la institución: no intervenía en la selección de los profesores y directivos, ni realizaba inspecciones periódicas ${ }^{35}$. El conflicto derivó en el cierre del Colegio en 1885 por decisión de los propios jesuitas e inmediatamente esto dio pie a una árida disputa por el destino del edificio. La prensa anticlerical denunció una vez más los «peligros» del jesuitismo y clamó por la devolución del edificio a la provincia, y el gobierno nacional, por su parte, propuso varios usos alternativos para las instalaciones, entre ellos el establecimiento de un Colegio Nacional. De hecho el propio rector jesuita, José Reinal, evaluaba de manera muy poco optimista la situación y conside-

33 Mensaje del Sr. Vice-Gobernador Cándido Pujato a la Legislatura, 18 de mayo de 1882 y 25 de mayo de 1883, documento de archivo editado en AA.VV., 1973b, vol. VI: 121122 y $142-143$.

34 Sobre la escrituración: Stoffel, 2004.

35 Para seguir el conflicto: Furlong, 1962, vol. III y IV: 546-556. 
raba que tarde o temprano tendrían que abandonar el edificio. Le parecía lógico además que, dada la inversión realizada, el gobierno quisiera ocupar las instalaciones del Colegio para darles un destino útil. Por entonces, recrudecieron en la prensa - principalmente en El Mensajero- denuncias que acusaban a los jesuitas de propagar el «oscurantismo»y «herejías antisociales y antifilosóficas»y, más mundanamente, de desviar fondos destinados al Seminario para sostener el colegio. Resignado, Reinal consideró que había llegado la hora de abandonar Santa Fe pero el gobernador Gálvez, un ex alumno del Colegio, se opuso y brindó su apoyo a los religiosos. En su opinión, los jesuitas debían continuar en el edificio porque si bien se había cerrado el Colegio aún funcionaba la Facultad de Jurisprudencia y el Seminario Diocesano. Gálvez defendió públicamente la permanencia de los jesuitas y realizó varias presentaciones ante el Ministerio de Instrucción Pública para lograr la reapertura de la institución, aumentando de paso su injerencia sobre la Facultad de Jurisprudencia, tal como se discutía desde tiempos de Servando Bayo. De hecho, por esos años el Estado provincial comenzó a administrar de manera directa la Facultad, designando al plantel docente y a las principales autoridades. Medidas que, más allá del apoyo público dado a los jesuitas, significaban su relegamiento a un segundo plano. Poco después, con la creación de la Universidad en 1889, la Facultad quedó plenamente sujeta al Estado.

Paralelamente, en lo referente al Colegio, las negociaciones siguieron su curso y el gobierno nacional propuso un acuerdo: reconocería a los jesuitas si el gobierno nombraba al rector y a los profesores pero Reinal se negó. El gobierno provincial cedió entonces el uso de parte del edificio al gobierno nacional y continuó realizando infructuosas presentaciones al Ministerio de Instrucción Pública hasta que, transcurridos algunos años, el Colegio fue reabierto aunque sin el reconocimiento de sus títulos.

Finalmente, tras la visita de Carlos Pellegrini en 1891, el gobierno provincial logró la validación de los títulos. Los jesuitas, por su parte, tuvieron que realizar algunas concesiones, como aceptar las inspecciones del Ministerio y reformar sus planes de estudio pero, al mismo tiempo, lograron mantener buena parte de los privilegios que, en tiempos de Wilde, habían motivado el conflicto. Materias tales como Doctrina Cristiana, Religión y Moral o Religión demostrada siguieron siendo consideradas asignaturas obligatorias y la administración del Colegio, incluida la designación del rector y el plantel docente, otrora uno de los principales motivos de controversia, siguió en manos de la Orden ${ }^{36}$.

36 Mensaje del Sr. Gobernador José Gálvez a la Legislatura, 19 de mayo de 1887; 17 de mayo 1888 y 23 de mayo de 1889, documentos de archivo editados en AA.VV., 1973b, vol. VI: 201-203, 254-257 y 279-280. 
Consideraciones finAles. REFLEXIONANDO EN TORNO A LA IMAGEN DE LA «ARGENTINA LIBERAL»

En los términos de Jean Baubérot, las décadas de 1860, 1870 y 1880 permiten explorar la emergencia de lo que cabría definirse como un segundo umbral de laicidad, proceso íntimamente ligado a la construcción misma del Estado y la Iglesia ${ }^{37}$.

En Santa Fe, como se vio, lo que impulsó las medidas de Oroño no fueron sus supuestas concepciones «liberales» o «anticatólicas»-como señalaban amigos y enemigos- sino la necesidad de responder a los desafíos planteados por el avance del proceso de colonización. Como reflexionaba José María Gutiérrez polemizando con Félix Frías: «El gobierno de Santa Fe no era revolucionario $[\ldots]$ era lógico».

Se trataba de desafíos derivados, como vimos, de la materialidad que hacia 1860 adquirió el proceso de «secularización revolucionaria» basado en la desnaturalización entre religión y política y la tendencial separación entre ciudadano y fiel. En otras palabras, las causas de las políticas laicizadoras de Oroño -independientemente de sus opiniones- residían en el resquebrajamiento concreto, real y palpable del régimen de cristiandad derivado del enérgico impulso dado a la colonización en una provincia que, como Santa Fe, dependía más que otras de su éxito. Por primera vez, la campaña santafesina alojó a un número visible de protestantes franceses, belgas y suizo-alemanes que pretendían celebrar su culto en templos propios, contraer matrimonio y enterrar a sus muertos sin abjurar de su religión. Por entonces, además, el giro intransigente que desde Roma se irradiaba al mundo se tradujo en sucesivas condenas de Gelabert a la masonería que, dada su importante presencia en Santa Fe y Entre Ríos, derivaron en crecientes roces y conflictos ${ }^{38}$.

El proceso de transformación de la cristiandad en modernidad religiosa adquirió así, en la Santa Fe de la década de 1860, una dimensión más concreta y palpable que en otras provincias argentinas e hizo consecuentemente más imprescindible la sanción de leyes que aseguraran un piso de laicidad mayor: entre ellas, la estatización de los cementerios y el matrimonio civil. El gobierno, tras los roces con el Colegio de la Inmaculada y el Convento de San Lorenzo, consciente del difícil camino que emprendía, se movió con suma cautela atendiendo las demandas de Gelabert y destacando la importancia del catolicismo como agente civilizador y factor de unidad social y política. Sin embargo, frente a la ley de matrimonio civil, la pastoral de Gelabert adquirió

37 Sobre el proceso: Lida, 2007.

38 Bonaudo, 2010. 
una particular dureza, al punto en que tanto Oroño como sus legisladores fueron excomulgados. Tras bambalinas, empero, el Obispado intentó negociar, al menos en parte. Primero, porque los recursos que obtenía del gobierno eran considerados indispensables y se temía perderlos desencadenando, tal vez, medidas más radicales como la separación de la Iglesia y el Estado. De igual manera, por cierto, se comportaron los jesuitas. Reaccionaron con vehemencia cuando se intentó regular sus planes de estudio -dando por rescindido el contrato con el gobierno provincial- pero en los hechos, como se vio, la ruptura fue mucho menos definitiva: el gobierno siguió pagando las becas entregadas y terminó las obras iniciadas y, por su parte, los jesuitas aceptaron modificar parcialmente los planes de estudio. Pasado el encontronazo, con el cambio de gobierno, las becas no sólo se restituyeron plenamente sino que aumentaron en número. Los jesuitas, por su parte, si bien continuaron cuestionando la injerencia del Estado en la confección de sus planes -ahora del Nacional-, acabaron introduciendo, apoyados por el gobierno provincial, los cambios necesarios para que tras varias idas y venidas sus programas y títulos obtuvieran nuevamente el debido reconocimiento oficial.

Segundo, porque, a juzgar por las negociaciones del enviado de Gelabert, la propia Iglesia parecía estar al menos en parte resignada a que un régimen de cristiandad pleno ya no podía ser sostenido y que, precisamente, lo más conveniente era hacer algunas concesiones consolidando todo lo posible el lugar del catolicismo y de la Iglesia en el nuevo orden social, político y económico. En el caso de la ley de municipalización de los cementerios, por ejemplo, el centro neurálgico de la discusión no residió tanto en la propiedad de los mismos -y en su virtual estatización- como en el cobro de los servicios religiosos. Una importante fuente de ingresos que, dada la escasez de recursos del clero secular, la Iglesia no podía darse el lujo de perder. Gelabert, de hecho, se mostró dispuesto a aceptar por lo bajo la municipalización y el registro civil a condición de que el Estado le asegurara seguir cobrando las tarifas habituales independientemente de las que éste decidiera fijar en su beneficio. Se pretendía incluso, a juzgar por la propuesta del Provisor, que fuera el propio Estado el que asegurara el cobro. Una posición que, tal vez, aunque a contramano del proceso de secularización, Oroño hubiera aceptado de no estallar el alzamiento armado que, como vimos, tenía claramente otras motivaciones.

Pasados los momentos de tensión y derogada la ley de matrimonio civil, en la década de 1870, los vínculos entre el Estado provincial en construcción y la joven Iglesia de Santa Fe se estrecharon más firmemente. Las relaciones con los jesuitas siguieron siendo consideradas estratégicas por los diferentes gobernadores -que hicieron del Colegio de la Inmaculada el principal forma- 
dor de las élites locales-, y desde el Estado se aportó de diferentes maneras al proceso de construcción de la Iglesia. Se destinaron partidas especiales para templos, se otorgaron becas y subsidios a los colegios católicos y beneficios fiscales a los emprendimientos colonizadores que donaran terrenos al Obispado.

En este contexto, las leyes laicas de la década de 1880 no causaron conflictos serios ni revueltas como en 1860. En parte porque, más allá de los discursos combativos de parte del clero -basados en el Syllabus y la retórica intransigente de la época-, el consenso en torno a la inevitabilidad de que el Estado asumiera funciones como las del Registro Civil o sancionara leyes como la del matrimonio civil era ya mucho más generalizado. El propio proceso de crecimiento económico, las tasas inmigratorias de la década de 1880 -por cierto, mucho más favorables a la Iglesia-y la inserción de la Argentina en el mercado mundial hacían difícil al catolicismo mantener posiciones totalmente intransigentes. Las voces, por supuesto, se oyeron de todos modos -tal el caso por ejemplo, de la de Monseñor Clara desde Córdoba- pero no por ello los cambios dejaron de ser vistos al mismo tiempo y en un cierto grado como indetenibles.

En este sentido, la relativa calma que vivió Santa Fe durante la década de 1880 fue una consecuencia de los acuerdos de las élites políticas provinciales en relación a los «contenidos» de ese segundo umbral de laicidad, al que, dicho sea de paso, la Iglesia parecía no temerle tan seriamente como declamaba. Después de todo, dicho umbral le aseguraba -como demuestran los debates de la convenciones constituyentes provinciales de 1863, 1872, 1883 y 1890- un claro lugar de privilegio, además de contribuir materialmente a su propia conformación como institución centralizada y moderna ${ }^{39}$.

Diferente era la cuestión de la ley de educación laica que la Iglesia se negaba a aceptar tajantemente como parte de ese «segundo umbral». En Santa Fe, sin embargo, estos conflictos, que sacudían la opinión católica a nivel nacional y que se convirtieron en iconos de la década, se vivieron sólo muy tenuemente. La prensa alimentó una retórica anticlerical y antijesuita algo más vigorosa - por ejemplo, en el caso de El Mensajero- pero las relaciones con el gobierno y las élites políticas locales fueron en todo momento armónicas. Básicamente porque el Estado provincial no incorporó a sus leyes de 1884 y 1886 la impronta laicizadora de la ley nacional ni dio muestras de querer hacerlo. Por el contrario, la enseñanza de la religión se consideró en todo momento primordial y el apoyo a la educación católica fue firme, indiscutido y además muy palpable: más becas, más subsidios y bonos de edificación,

39 AA. VV., 1973a. 
apoyo a las congregaciones religiosas que comenzaban a instalar colegios, reconocimiento oficial al catolicismo en la educación, etc. Tendencias que se profundizaron durante la década de 1890 y se potenciaron con la implementación, en el caso de Santa Fe durante el gobierno de Luciano Leiva, de la educación patriótica en las escuelas. Según sugieren los escritos de Ramón Lassaga, esta educación patriótica ya comenzaba a incluir lecturas catolizantes e hispanistas del pasado nacional.

En resumidas cuentas, este segundo umbral, que incluyó la laicización de algunas funciones básicas por parte del Estado, dejó afuera en el caso de Santa Fe a la educación laica, el principal motivo de discordia a nivel nacional. La idea de la supuesta «retracción» de la marea laicista hacia 1890 debiera ser entonces revisada, al menos para el caso de Santa Fe -aunque probablemente también para otros casos provinciales-, porque tal «marea» resultó en concreto mucho más tenue que a nivel nacional. La educación laica quedó afuera de la discusión del segundo umbral y hubo que esperar al menos dos décadas para que dichos consensos comenzaran a horadarse, a través de iniciativas como el proyecto de ley de educación laica de 1915 o la reforma constitucional de 1921, ambos finalmente incapaces de torcer las cosas.

Asimismo, el caso sugiere también que -como se viene discutiendo- es necesario revisar el cuadro marco de una «Argentina liberal» con «hegemonía laica», en la cual el gobierno de Oroño habría sido una suerte de «adelanto» ${ }^{40}$. Primero, porque los diferentes gobernadores de la provincia, tanto Cullen y Oroño del Club Libertad como Bayo, Iriondo o Gálvez del Club del Pueblo coincidieron ampliamente en reconocer el papel civilizador del catolicismo y la centralidad que le cabía en la educación y en el presupuesto estatal ${ }^{41}$. Segundo, porque considerar como «liberales» a estas élites -incluidos Cullen y Oroño- plantea serias dificultades para explorar los modos en que, en los hechos, dichos gobiernos entablaron relaciones con el Poder Eclesiástico. A decir verdad, las posiciones estrictamente liberales en cuanto a las relaciones Estado-Iglesia, mirando con algo más de detenimiento, fueron más bien minoritarias en todo el período. La crisis desatada en 1867, por ejemplo, no derivó -como solían decir los librepensadores- en intentos claros por avanzar hacia un modelo de «secularización liberal». Por el contrario, el conflicto fortaleció un discurso que, aunque ambiguo, exhibió marcas bastante definidas de una tradición galicana ciertamente más vigorosa de lo proclamado. Oroño, a fin de cuentas, no amenazó al obispo y al clero con la separación sino con

40 El debate general ha sido planteado recientemente en: Di Stefano, 2010a: 14ss.

41 Sobre los debates en torno al presupuesto de culto: Lida, 2007. 
la cárcel, exigiéndoles acatar las resoluciones del gobierno en su calidad de funcionarios públicos. Argumentos similares empleó para solicitar el reemplazo del párroco de Rosario poco antes del conflicto o para «suspender» al cura de Villa Constitución y pedir su reemplazo poco después de la municipalización de los cementerios. De igual manera, cuando cuestionó públicamente a Gelabert por excomulgarlo no lo hizo en nombre de una mayor separación de la Iglesia y el Estado sino de la correcta aplicación del derecho canónico que supuestamente Gelabert desconocía.

Finalmente, la construcción de ese segundo umbral en plena «Argentina liberal» e incluso en el momento laico por excelencia, no implicó de parte del poder político de Santa Fe ninguna discusión seria sobre el lugar de la religión en el orden social y político. En ningún momento el catolicismo dejó de ser considerado la base de la sociedad y del progreso y, aun respetando la libertad de cultos - como señalaban Servando Bayo y Simón de Iriondo-, el Estado debía propender a mantener la unidad religiosa considerada garantía de unidad social y política. En este marco, la educación laica no mereció, como vimos, mayores discusiones. De igual manera, ninguna de las cinco convenciones constituyentes entre 1863 y 1900, dio pie a debates sobre las relaciones Iglesia-Estado o sobre la necesidad de instaurar la educación laica. Por el contrario, la religión católica fue considerada sin objeciones la «religión de la Provincia», merecedora del «mayor de los respetos».

Recién durante el período de entreguerras, algunos de los miembros de las élites políticas de la provincia -partícipes, como en el caso de Manuel Menchaca, de los centros de librepensamiento de Santa Fe- comenzaron a discutir las características y alcances del segundo umbral establecido hacia 18801890 .

Cabría agregarse, por último, que fue en los años del llamado «renacimiento católico» cuando, por primera vez, Santa Fe contó con una Constitución liberal que separó en la órbita provincial Iglesia y Estado, suspendiendo la invocación a Dios en el preámbulo, declarando la neutralidad religiosa y estableciendo la laicidad de la educación. Lo que, aunque por breve tiempo, derivó en la sanción de una ley de educación laica, vigente entre 1934 y 1935. Llamativamente, estos intentos por rediscutir los alcances del «segundo umbral» llegaron, como en Tucumán y Entre Ríos, en el preciso momento en que supuestamente la «Argentina liberal y laica» agonizaba. Una doble paradoja que invita sin dudas a seguir investigando y debatiendo en torno a algunas de nuestras más fuertes e influyentes interpretaciones. 
BIBLIOGRAFÍA

AA.VV., Colección de Documentos para la Historia de Santa Fe. Actas de convenciones constituyentes: 1841, 1856, 1863, 1873, 1883, vol. I (Primera Parte), Santa Fe, Edición en Homenaje del Cuarto Centenario de la Fundación de Santa Fe, $1973 a$.

AA.VV., Historia de las Instituciones de la Provincia de Santa Fe, vol. VI, Santa Fe, Comisión Redactora, 1973 b.

Auza, Néstor, Católicos y liberales en la generación del ochenta, Buenos Aires, EDUCA, 2007.

Barsky, Osvaldo y Gelman, Jorge, Historia del Agro Argentino, Buenos Aires, Mondadori, 2005.

Baubérot, Jean, "Te Evolution of Secularism in France: Between Two Civil Religions", Linell Cady y Elizabeth Shakman Hurd, Comparative Secularisms in a Global Age, New York, McMillan, 2010: 57-68.

Blancarte, Roberto, "Laicidad y laicismo en América Latina”, Estudios Sociológicos, XXVI/1 (México, enero-abril, 2008): 139-164.

Bonaudo, Marta (dir.), La organización productiva y política del territorio provincial, Santa Fe, 1850-1912, Rosario, La Capital-Prohistoria, 2006.

Bonaudo, Marta, “Sociabilidades que construyen republicas? La masonería como espacio de agregación sociocultural de inmigrantes y criollos en la Argentina decimonónica", Andrea Reguera y Elda González Martínez (comps.), Descubriendo la Nación, Buenos Aires, Biblos, 2010.

Bonaudo, Marta, "Liberales, masones ¿subversivos?”, Revista de Indias, LXVII/240 (Madrid, 2007): 403-432.

Bruno, Cayetano, Historia de la Iglesia Argentina, vol. VII, Buenos Aires, Editorial Don Bosco, 1981.

De Marco, Miguel Ángel, "Introducción”, Nicasio Oroño. Obras Completas, vol I, Santa Fe, UNL, Academia Nacional de la Historia, 2004.

Di Stefano, "Disidencia religiosa y secularización en el siglo XIX Iberoamericano: cuestiones conceptuales y metodológicas", Projeto História, 37 (San Pablo, 2008): 157-178.

Di Stefano, "El pacto laico argentino", PolHis, 8 (Buenos Aires, 2011b): 80-89.

Di Stefano, El púlpito y la plaza, Buenos Aires, Siglo XXI, 2004.

Di Stefano, Roberto, "Por una historia de la secularización y la laicidad en la Argentina”, Quinto Sol, XV/1 (La Pampa, 2011a): 1-31 
Di Stefano, Roberto, Ovejas Negras. Historia de los anticlericales argentinos, Buenos Aires, Sudamericana, 2010.

Diotallevi, Luca, Il rompicapo della secolarizzazione italiana, Rubbetino, 2001.

Furlong, Guillermo, Historia del Colegio de la Inmaculada de la Ciudad de Santa $\mathrm{Fe}$, vols. III y IV, Buenos Aires, Edición de los Ex Alumnos, 1962.

Gallo, Ezequiel, La pampa gringa, Buenos Aires, Edhasa, 2004.

Gallo, Ezequiel, Vida, propiedad, libertad. Reflexiones sobre el liberalismo clásico y la historia, Buenos Aires, Eduntref, 2008.

Lida, Miranda, "El presupuesto de culto en la Argentina y sus debates. Estado y sociedad ante el proceso de construcción de la Iglesia (1853-1880)", Andes, 18 (Salta, 2007b): 49-75.

Lida, Miranda, "Una Iglesia a la medida del Estado: la formación de la Iglesia Nacional en la Argentina", Prohistoria, 10 (Rosario, 2007a): 27-46.

Lida, Miranda y Mauro, Diego (coords.), Catolicismo y sociedad de masas en Argentina: 1900-1950, Rosario, Prohistoria, 2009.

Lida, Miranda, "El catolicismo de masas en la década de 1930. Un debate historiográfico", Sara Amenta y Cynthia Folquer (eds.), Sociedad, cristianismo y politica. Tejiendo historia locales, Salta, CEPIHA, 2010.

Lynch, John, "La Iglesia católica en América Latina, 1830-1930”, Leslie Bethell (ed.), Historia de América Latina. América Latina: cultura y sociedad, 1830-1930, Tomo VIII, Barcelona, Cambridge University Press, Crítica, 1991: 65-122.

Mallimaci, Fortunato, "Los diversos catolicismos en los orígenes de la experiencia peronista", Fortunato Mallimaci, y Roberto Di Stefano, Religión e imaginario social, Buenos Aires, Manantial, 2001: 215-232.

Mallimaci, Fortunato, "Nacionalismo católico y cultura laica en Argentina”, Roberto Blancarte (coord.), Los retos de la laicidad y la secularización en el mundo contemporáneo, México, El Colegio de México, 2008: 239-262.

Mallimaci, Fortunato, "Catolicismo y liberalismo: las etapas del enfrentamiento por la definición de la modernidad religiosa en América Latina”, J. P. Bastian (coord.), La modernidad religiosa. Europa latina y América Latina en perspectiva comparada, México, FCE, 2004: 19-44.

Mauro, Diego, De los templos a las calles. Catolicismo, sociedad y politica. Santa Fe, 1900-1937, Santa Fe, UNL, 2010.

Mauro, Diego, "Imágenes especulares. Educación, laicidad y catolicismo en Santa Fe, 1900-1940”, Prohistoria, 12 (Rosario, 2008): 103-116.

Martínez, Ignacio, "De la monarquía católica a la nación republicana y federal. Soberanía y patronato en el Río de la Plata. 1753-1853", Secuencia, 76 (México, 2010): 15-38. 
Pasquali, La instauración liberal: Mitre, Urquiza y un estadista olvidado, Nicasio Oroño, Buenos Aires, Planeta, 2003.

Pasquali, Patricia, "La oposición Rosario-Santa Fe y la pugna ideológica entre católicos y liberales en la década del ochenta", Sexto Congreso Nacional y Regional de Historia Argentina, Río Cuarto, Academia Nacional de la Historia, 1987: 165177

Ruiz Moreno, Isidoro, Elecciones y Revolución. Oroño, Urquiza y Mitre, Claridad, 2006.

Simian, Susana, "Contribución al estudio del gobierno de Nicasio Oroño, 18651868", Oscar Videla y Berta Wexler (comps.), Conflicto y gobierno. Acerca de la gestión de Nicasio Oroño en Santa Fe, Villa Constitución, ISP, 2004: 9-58.

Sonzogni, Élida, "La secularización antes de la secularización. Las reformas liberales del gobierno de Oroño. Santa Fe, 1865-1868", Oscar Videla y Berta Wexler (comps.), Conflicto y gobierno. Acerca de la gestión de Nicasio Oroño en Santa $\mathrm{Fe}$, Villa Constitución, ISP, 2004: 59-78.

Stoffel, Edgar, "Construcción de templos y capillas en la pampa gringa santafesina", Res Gesta, 42 (Rosario, 2007): 263-280.

Woodhead, Linda (ed.), Peter Berger and the study of religión, London, Routledge, 2001 .

Fecha de recepción: 17 de octubre de 2012.

Fecha de aceptación: 21 de diciembre de 2012.

\section{Secularization Processes in Santa Fe (Argentina): 1860-1900. Considerations on the "Liberal and Secular Argentina"}

This article aims to contribute to the history of secularization in Argentina. It highlights the need of deeper research on the processes of secularization that, in different ways, were developed during the second half of the 19th century. In particular, the paper focuses on the province of Santa Fe from 1860 to 1900 when, in Jean Baubérot terms, a «second secularization threshold» was reached.

KeY words: secularization; laicization; secularization threshold; Catholic Church; civil marriage. 